\title{
Beta-2-glycoprotein I as a biomarker for sepsis in critically ill patients in the intensive care unit: a prospective cohort study
}

\author{
Irene T. Schrijver ${ }^{1 *}$ D, Hans Kemperman ${ }^{2}$, Mark Roest ${ }^{3}$, Jozef Kesecioglu ${ }^{1}$ and Dylan W. de Lange ${ }^{1,4}$
}

Keywords: B2GPI, Biomarkers, Sepsis, Critical care, ICU, SIRS, Apolipoprotein H

To the editor,

It is difficult to diagnose sepsis in critically ill patients admitted to the intensive care unit (ICU). A biomarker could help in sepsis identification and guide antibiotic use. A prognostic biomarker that identifies high-risk patients for the development of sepsis or nosocomial infections could help prevent those outcomes. However, current sepsis biomarkers often portray systemic inflammation and are unspecific to infection [1].

The complement system is essential for defending against infections, yet it can also contribute to severe sepsis outcomes [2]. A potential complement regulator is beta-2-glycoprotein I (B2GPI). B2GPI, also known as apolipoprotein $\mathrm{H}$, exerts a complement control after binding to specific surfaces such as apoptotic cells and bacteria. After the conformational change of B2GPI, monocytes can clear B2GPI, resulting in lower B2GPI plasma levels. Supporting this, previous studies found lower levels of B2GPI after lipopolysaccharide (the main component of the outer membrane of bacteria) infusion in humans and male mice [3, 4]. Therefore, we hypothesized that B2GPI levels can differentiate between sepsis and non-infectious critically ill patients. To test this and to determine the discriminative and prospective value of B2GPI as a sepsis biomarker, we conducted a prospective study.

We included 313 critically ill adult patients (defined as two or more systemic inflammatory response syndrome (SIRS) criteria upon admission) with an anticipated ICU stay of more than $24 \mathrm{~h}$ (Table 1) [5]. In $48 \mathrm{~h}$ following ICU admission, blood was sampled twice to measure the maximum level of B2GPI using a semi-automated sandwich ELISA on a Freedom EVO platform (Tecan) with goat anti-human beta-2-glycoprotein-1 and HRPcoupled goat-human beta-2-glycoprotein-1 antibodies (both Cedarlane). Supersignal West Pico Chemiluminescent substrate (Thermo Scientific) was added, and the luminescence signal was measured using a Spectramax-L microplate reader (MDS Analytical). The outcomes "no sepsis," "sepsis," and "septic shock" were defined according to the sepsis-3 criteria. The outcome "proven infection" was derived from Centers for Disease Control (CDC) algorithms. Statistical analyses were performed using SPSS version 21.0 and $\mathrm{R}$ version 3.6.1.

* Correspondence: i.t.schrijver@gmail.com

${ }^{1}$ Department of Intensive Care Medicine, University Medical Centre, University of Utrecht, Heidelberglaan 100, 3584 CX Utrecht, The Netherlands Full list of author information is available at the end of the article 
Table 1 Descriptive characteristics, medians (IQR) or N (\%)

\begin{tabular}{|c|c|c|c|c|}
\hline Characteristic & No sepsis & Sepsis & Septic shock & $P$ value \\
\hline Number of patients & 180 & 75 & 47 & $n / a$ \\
\hline Gender, male & $113(62 \%)$ & $47(38 \%)$ & $33(67 \%)$ & 0.778 \\
\hline Age (years) & $60(23)$ & $61(28)$ & $65(25)$ & 0.656 \\
\hline \multicolumn{5}{|l|}{ Diagnosis at admission } \\
\hline Trauma & $8(4 \%)$ & $10(13 \%)$ & $5(10 \%)$ & \multirow[t]{4}{*}{$0.028^{*}$} \\
\hline Infection (suspicion of) & $40(22 \%)$ & $20(26 \%)$ & 19 (40\%) & \\
\hline Post surgery & 35 (19\%) & $11(15 \%)$ & $6(12 \%)$ & \\
\hline Others & $97(54 \%)$ & $35(46 \%)$ & $18(38 \%)$ & \\
\hline \multicolumn{5}{|c|}{ Severity of illness (at admission) } \\
\hline Mechanical ventilation & $104(86 \%)$ & $43(78 \%)$ & $26(65 \%)$ & $<0.001^{*}$ \\
\hline APACHE IV score & $70(44)$ & $74(38)$ & $93(44)$ & $0.003^{*}$ \\
\hline SOFA score & $6(5)$ & $5(5)$ & $11(5)$ & $<0.001^{*}$ \\
\hline 30-day mortality & $39(21 \%)$ & $19(25 \%)$ & 17 (34\%) & 0.157 \\
\hline ICU stay (days) & $10(10)$ & $8(10)$ & $8(9)$ & 0.267 \\
\hline Gram-negative infection & $25(14 \%)$ & $25(33 \%)$ & $22(45 \%)$ & $<0.001^{*}$ \\
\hline$\beta 2$ Glycoprotein-1 ( $\mu \mathrm{g} / \mathrm{mL})$ & $198(313)$ & $165(195)$ & 129 (149) & $<0.001^{*}$ \\
\hline CRP (mg/L) & $187(166)$ & $245(200)$ & $290(168)$ & $<0.001^{*}$ \\
\hline Procalcitonin & $1.0(3.0)$ & $2.9(8.1)$ & $4.5(35.8)$ & $<0.001^{*}$ \\
\hline Leukocytes (× 109/L) & $16(9)$ & $16(10)$ & $16(10)$ & 0.937 \\
\hline
\end{tabular}

Mechanical ventilation direct upon admission; IQR interquartile range, MPO myeloperoxidase, APACHE IV Acute Physiology and Chronic Health Evaluation IV severity of illness model, CRP C-reactive protein, SOFA Sequential Organ Failure Assessment. Baseline characteristic comparisons were made using Mann-Whitney $U$, chi-square, or Kruskal-Wallis tests for skewed variables and Student's $T$ test or chi-square test for normal distributed variables. ${ }^{*} P<0.05$

We found that B2GPI levels were significantly lower in patients with sepsis compared with patients without sepsis. Patients with a septic shock had lower B2GPI levels compared with patients with solely sepsis (Fig. 1a). Patients with an infection had lower levels of B2GPI (Fig. 1b). Patients within the highest tertile of B2GPI levels developed $44 \%$ fewer infections compared with the lowest tertile ( $P=0.007$, Fig. $1 \mathrm{~d})$ in the 10 -day follow-up. There was no significant difference in B2GPI levels between survivors and non-survivors (Fig. 1c) and between gram-positive and gram-negative sepsis (162 [IQR 87275] vs 131 [IQR 96-221]).

We showed that B2GPI could differentiate between patients with and without sepsis. Moreover, patients with lower B2GPI levels in the first $48 \mathrm{~h}$ developed more nosocomial infections. This suggests that B2GPI may be a novel biomarker for both diagnosing sepsis and predicting nosocomial infections. This study took place in a general ICU; therefore, it seems feasible that our results could be generalizable to other ICUs.

Most biomarkers spike in sepsis; therefore, the lower B2GPI levels we found are relatively unique. Other biomarkers that decrease in sepsis are the inter-alpha inhibitor protein, lysophosphatidylcholine, and uric acid
$[1,6]$. However, currently, they are not used in clinical practice.

In summary, this is the first study that showed the value of the B2GPI biomarker in ICU patients with both a discriminative (for sepsis) and predictive (for nosocomial infections) role. Potentially, B2GPI can be helpful in diagnosing sepsis and stratifying ICU patients for infection risk.

\section{Abbreviations}

B2GPI: Beta-2-glycoprotein I; CDC: Centers for Disease Control; ICU: Intensive care unit; SIRS: Systemic inflammatory response syndrome

\section{Acknowledgements}

Not applicable.

\section{Authors' contributions}

MR, JK, and DWdL designed the study; HK and DWdL collected the data; ITS and DWdL analyzed and interpreted the data and performed the statistical analysis; ITS drafted the article; HK, MR, JK, and DWdL revised the article critically; and all authors gave final approval of the manuscript to be published.

\section{Funding}

The authors received no financial support for the research, authorship, and/ or publication of this article.

\section{Availability of data and materials}

The datasets used and/or analyzed during the current study are available from the corresponding author on reasonable request. 


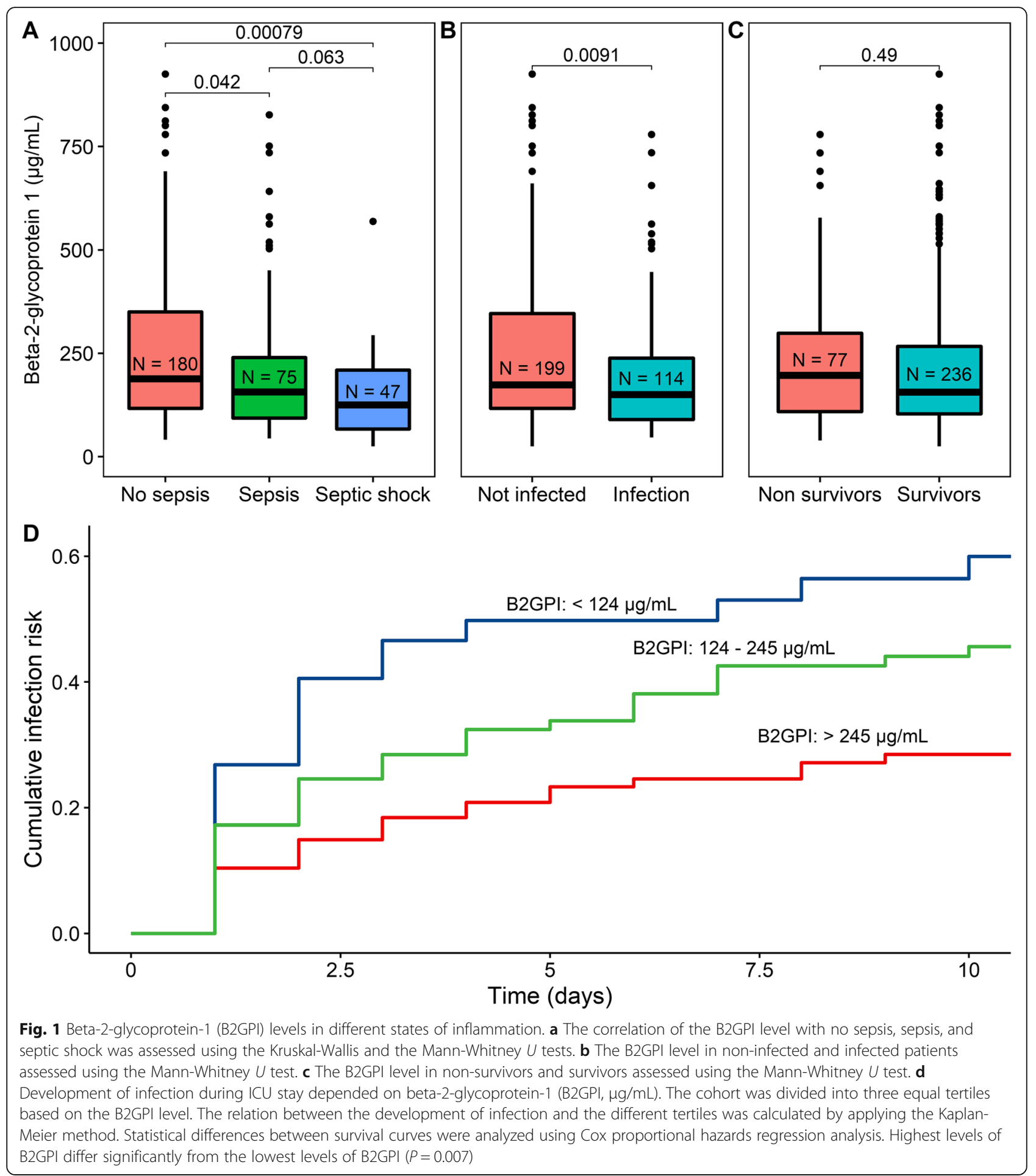




\section{Ethics approval and consent to participate}

The study methods were submitted to and approved by the institutional review board of the University Medical Centre Utrecht. It waived the need for informed consent (University Medical Centre Utrecht Institutional Review Board research protocol 108-188). The study was conducted in accordance with the Declaration of Helsinki.

\section{Consent for publication}

Not applicable.

\section{Competing interests}

The authors declare they have no conflict of interest.

\section{Author details}

'Department of Intensive Care Medicine, University Medical Centre,

University of Utrecht, Heidelberglaan 100, 3584 CX Utrecht, The Netherlands. ${ }^{2}$ Department of Clinical Chemistry and Hematology, Central Laboratory (CDL), University Medical Centre, University of Utrecht, Heidelberglaan 100, 3584 CX Utrecht, The Netherlands. ${ }^{3}$ Synapse B.V., Maastricht, The Netherlands. ${ }^{4}$ Dutch Poisons Information Center (DPIC), University Medical Center,

University of Utrecht, Heidelberglaan 100, 3584 CX Utrecht, The Netherlands.

Received: 13 May 2020 Accepted: 4 June 2020

Published online: 15 June 2020

\section{References}

1. Pierrakos C, Vincent JL. Sepsis biomarkers: a review. Crit Care. 2010;14(1):R15. https://doi.org/10.1186/cc8872.

2. Markiewski MM, DeAngelis RA, Lambris JD. Complexity of complement activation in sepsis. J Cell Mol Med. 2008;12(6A):2245-54.

3. El-Assaad F, Qi M, Gordon AK, Qi J, Dong S, Passam F, et al. Beta 2glycoprotein I protects mice against gram-negative septicaemia in a sexually dimorphic manner. Sci Rep. 2017;7(1)8201.

4. Agar C, de Groot PG, Morgelin M, Monk SD, van Os G, Levels JH, et al. $\beta_{2^{-}}$ glycoprotein I: a novel component of innate immunity. Blood. 2011;117(25): 6939-47.

5. Hyseni A, Kemperman H, de Lange DW, de Groot PG, Linssen M, Kesecioglu $J$, et al. Increased mortality in systemic inflammatory response syndrome patients with high levels of coagulation factor VIla. J Thromb Haemost. 2013;11(12):2111-7.

6. Mecatti GC, Messias MCF, de Oliveira Carvalho P. Lipidomic profile and candidate biomarkers in septic patients. Lipids Health Dis 2020 13;19(1):68.

\section{Publisher's Note}

Springer Nature remains neutral with regard to jurisdictional claims in published maps and institutional affiliations.

Ready to submit your research? Choose BMC and benefit from:
- fast, convenient online submission
- thorough peer review by experienced researchers in your field
- rapid publication on acceptance
- support for research data, including large and complex data types
- gold Open Access which fosters wider collaboration and increased citations
- maximum visibility for your research: over 100M website views per year
At BMC, research is always in progress.
Learn more biomedcentral.com/submissions

